\title{
Exploring the Effect of Syntactic Alignment on Chinese-English Bilinguals' Code- switched Sentence Production
}

\author{
Mengling Xu, Huzhou University, China
}

\begin{abstract}
As one of the most common language phenomena in bilingual settings, code-switching has been studied widely to explore its nature and features. In the current study, the author set out to explore the effect of syntactic alignment on Chinese-English bilinguals' code-switched sentence production using a picture-describing task with a structural priming paradigm. The structural priming paradigm has been frequently used to explore the mechanisms of sentence production. The effect of syntactic alignment was observed, indicating Chinese-English bilinguals were inclined to produce codeswitched sentences with the same syntactic structure between Chinese and English. The findings provide empirical evidence not only supporting structural priming during bilingual code-switched sentence production, but also extending the interactive alignment model (Pickering and Garrod, 2004) to interpret code-switching during bilingual sentence production. Implications for code-switching and bilingual sentence processing are discussed.
\end{abstract}

\section{KEYWORDS}

Chinese and English Code-Switching, Interactive Alignment Model, Sentence Production, Shared Word Order, Syntactic Alignment

\section{INTRODUCTION}

During the past two decades, as one of the most fascinating behaviors of bilinguals, code-switching has been widely investigated according to interdisciplinary approaches, such as grammatical (e.g., Poplack, 1980; MacSwan, 2000; Muysken, 2000; Myers-Scotton, 2002), socio-pragmatic (e.g., Blom \& Gumperz, 1972; Li et al., 1992; Myers-Scotton, 1993; Auer, 1998), cognitive (e.g., Meuter \& Allport, 1999; Costa \& Santesteban, 2004), and neurocognitive (e.g., Paradis, 1997; Abutalebi \& Green, 2007; van Hell \& Witteman, 2009) (see Isurin et al., 2009 for a review). Also, as a hotly debated topic in the literature, the nature and mechanism underlying code-switching has been studied in terms of switching cost (e.g., Green, 1998; Costa \& Caramazza, 1999; Thomas \& Allport, 2000; Kroll et al. 2008), asymmetry of switching cost (e.g., Kroll \& Stewart, 1994; Spinks \& Gelder, 1994; Cheung \& Chen, 1998; Meuter \& Allport, 1999), time dimension (e.g., Costa \& Santesteban 2004; Orfanidou \& Sumner, 2005; Zield et al. 2006), and bilingual language representation (e.g., Francis, 1999; Hernandez et al., 2001; Abutalebi \& Green, 2007; Salamoura \& Williams, 2007). The Inhibitory Control Model 
(IC model, Green, 1998) has been proposed to interpret switching cost during code-switching, suggesting that in line with language tags, inhibition mechanism activates lexical representation of one language while inhibits lexical representation of another language at the same time. In this way, it requires additional time for bilinguals to inhibit current activated lexical representation, and to relieve current inhibited lexical representation during code-switching. So, switching cost is produced. In addition, compared with inhibiting lexical representation of proficient language, inhibiting lexical representation of non-proficient language is relatively weak, which results in asymmetry of switching cost. The IC model has been supported by behavioral and neuroimaging studies (Meuter \& Allport, 1999). Not assuming the inhibition mechanism, the language-specific selection hypothesis (Costa \& Santesteban, 2004) postulates that lexical representation of the non-responding language does not enter into competition during lexical selection, the selection mechanism only accesses to target words by lexical representation of the responding language, although both of two languages are activated during language production of proficient bilinguals. So, asymmetry of switching cost does not exist (Costa \& Santesteban, 2004). Based on this hypothesis, researchers have proposed that the selection mechanism is different between proficient and non-proficient bilinguals. On the one hand, proficient bilinguals use the language-specific selection mechanism during code-switching between two proficient languages or between proficient language and less-proficient language. They select words by different mechanisms according to different proficiency of the responding languages during language production (Costa, Santesteban and Ivanova, 2006). On the other hand, non-proficient bilinguals use the inhibitory control mechanism during code-switching between proficient and nonproficient languages. Hence, this language-specific selection hypothesis successfully explains the equivalent switching cost of two responding languages during code-switching of proficient bilinguals. However, asymmetry of switching cost still exists between proficient language and unfamiliar newlearned language during code-switching of proficient bilinguals, which could not be explained. Costa, Santesteban and Ivanova (2006) has further proposed the language-specific selection threshold hypothesis, suggesting that each language has its own threshold for mental lexicon such as activation level of the responding languages, and independent selection threshold of different languages. In order to deal with proficiency imbalance between the responding languages, speakers are more active and effective to mental lexicon representation of less proficient language during code-switching. Therefore, compared with the proficient language, it is much easier for the less proficient language to reach selection threshold. In short, proficiency imbalance among two responding languages results in faster selection of the less proficient language. This language-specific selection threshold hypothesis not only explains the equivalent switching cost of between two proficient languages (L1-L2), and/or between proficient and less proficient language (L2-L3) during code-switching of proficient bilinguals, but also explains the greater switching cost from non-proficient language to proficient language. As was noted above, a handful of studies have examined code-switching at lexical and/or sub-lexical level of language processing, studies address code-switching at sentence-level of language processing, however, are quite scarce. In daily language communication, code-switching happens frequently as bilinguals spontaneously and effortlessly use two and/or more different languages among coherent sentences in rich discourse situations (Wei, 2007; Gullberg, et al., 2009). Hence, an understanding of code-switching at sentence-level of language processing seems necessary.

According to the view that dialogue is the most nature and fundamental way of language usage in people's daily life, and the purpose of dialogue is not only to code information, but also to express ideas for mutual understanding, Pickering and Garrod (2004) have proposed the interactive alignment model to explain the cognitive mechanisms of dialogue processing. During dialogue processing, two interlocutors coordinate and interact with each other on the basis of their languages, and unconsciously build situation models (see Zwaan \& Radvansky, 1998 for details) to understand utterances. Two interlocutors' activated linguistic representations (semantics, lexicon, syntax, phonology, articulation) directly connect with situation models, and resonate during language processing, increasing the likelihood of activated linguistic representations to be selected again. The 
interconnection within and between two interlocutors enables interactive alignment to occur. In short, two interlocutors' representations interacts and aligns at multiple levels, and interactive alignment at one level affects interactive alignment at other higher and/or lower levels. Importantly, interactive alignment is automatic and primarily unconscious (Pickering \& Garrod, 2004), which facilitates language production by helping interlocutors make shortcuts during language production, such as interlocutors tend to produce linguistic expressions in the same way as their partners have produced before (Garrod \& Pickering, 2004; Schober, 2006). In other words, in accordance with interactive alignment, people could reuse preceding successful language conversation to develop subsequent language communication, in which two and/or more languages could be co-activated and in resonance at all levels of language processing (Pickering \& Garrod, 2004; Kroll et al., 2006; Kootstra et al., 2009). Code-switching involves combined use of co-activated languages, and occurs quite often because of high magnitude of co-activation. As discussed above, the interactive alignment model (Pickering \& Garrod, 2004) could be applied to explain language adaptation and accommodation, to specify the relationship and interaction between different levels of language processing during speech production and comprehension, and to examine the alignment of language choices within and between two and/ or different activated languages during code-switching of bilinguals (Kootstra et al., 2010). Hence, the interactive alignment model (Pickering \& Garrod, 2004) could be further applied as a theoretical basis to interpret the mechanisms of code-switching and bilingual language processing.

Studies on bilingual language processing have investigated whether or not bilinguals have one single shared language representation or separate language representations, in which syntactic coactivation and representation have been widely investigated using a structural priming paradigm (e.g. Bock, 1986; Pickering \& Branigan, 1999; Schoonbaert et al., 2007; Pickering \& Ferreira, 2008; Weber \& Indefrey, 2009). Structural priming is also called syntactic priming, which refers to the facilitation of syntactic processing that occurs when a sentence has the same syntactic structure as a preceding sentence (Pickering \& Branigan,1999). In other words, structural priming facilitates an increased tendency for speakers to repeat syntactic structures that have been used before by themselves or others during sentence production. Levelt and Kelter (1982) has found that people tend to respond to a question with a lexically and syntactically congruent answer. In the study of Branigan et al. (2000), the confederate produced a description like "teacher giving the book to the student", then some experimental subjects produced a description like "the waiter giving the banana to the soldier", whereas other subjects produced a description like "the clown handing the banana to the cowboy". The structural priming was considerably obvious when the verb was repeated, which demonstrated a lexical boost, that is, lexical alignment enhanced syntactic alignment. Also, in the study of Cleland and Pickering (2003), participants produced noun phrases like "the ship that's red" more often after hearing "the boat that's red" than "the desk that's red", which demonstrated a semantic boost, that is, semantic-related lexical items enhanced structural priming. In the structural priming study of passive sentences between Spanish and English by Hartsuiker et al. (2004), bilingual participants used an English passive more often after their partner used a Spanish passive than a Spanish active. In addition, structural priming has also been found in different populations, including adults (e.g., Branigan et al., 2000; Gries, 2005; Pardo, 2006), children (e.g., Huttenlocher et al., 2004), second language learners (e.g., McDonough, 2006; Costa et al., 2008) and deaf children (van Beijsterveldt $\&$ van Hell, 2009). Moreover, Ferreira and Bock (2006) has examined the role of alignment playing in structural priming during conversation. Pickering and Garrod $(2004,2006)$ has regarded structural priming as an important factor in the facilitation of alignment at all levels of linguistic representations, leading to successful communication. Furthermore, syntactic structures are often quite similar among different languages, and cross-language structural priming is more likely to occur in bilingual sentences with the same syntactic hierarchical structures (e.g., Loebell \& Bock, 2003; Hartsuiker et al., 2004; Desmet \& Declercp, 2006; Bernolet et al., 2007). Hence, providing a processing-based interpretation, cross-language structural priming could be applied to investigate how syntactic similarities affect syntactic representation in code-switching and bilingual sentence production. 
Taken jointly, the idea of co-activation of linguistic elements caused by processing interconnectivity is compatible with resonance assumed in the interactive alignment model (Pickering a\& Garrod, 2004). Cross-language structural priming enhances the integration of all the linguistic components among different languages, and activates syntactic representation of languages, resulting in syntactic alignment, and finally achieving interactive alignment. From this point of view, it is reasonable and feasible to explore bilingual code-switched sentence production using cross-language structural priming within the theoretical framework of the interactive alignment model (Pickering \& Garrod, 2004). Kootstra et al. (2010) studied the effect of syntactic alignment on Dutch-English code-switched sentence production. Code-switching between ideographic words (e.g., Chinese) and alphabetic words (e.g., English) are different from code-switching between and/or among alphabetic words. So, it is of great importance to explore code-switching between Chinese and English. To date, few of studies have given an attempt to investigate code-switching between Chinese and English during sentence production. Therefore, taking the interactive alignment model (Pickering \& Garrod, 2004) as the theoretical basis, the current study is designed to investigate the effect of syntactic alignment on Chinese-English bilinguals' code-switched sentence production, following the structural priming paradigm in the study of Branigan et al. (2007) and Kootstra et al. (2010). Specifically, the following two questions would be addressed: (1) Is there an effect of syntactic alignment on Chinese-English bilinguals' code-switched sentence production? (2) How does the effect of syntactic alignment influence Chinese-English bilinguals' code-switched sentence production?

\section{METHODS}

\section{Participants}

Forty-three postgraduates, majoring in English Language and Literature as well as Linguistics and Applied Linguistics in Foreign Languages at Ningbo University, participated in this experiment. Among them, 37 of whom are female and 6 are male. Their age ranges from 22 to 24 years old (M =22.5). They are native Chinese speakers, who started to learn English at the age of 10 or 11 years old, that is, they have learned English for twelve or thirteen years. They all have normal or correctedto-normal vision, without listening, speaking, reading or writing difficulties. It was the first time for them to participant in this kind of experiment.

\section{Materials}

The materials used in this experiment were randomly chosen from pictures used by Kootstra et al. (2010). Forty-four pictures of simple transitive events involving an agent, an action, an object and a patient were used, in which thirty-two pictures used as experimental trials, eight pictures used as filler trials and four pictures used as practice trials. To make sure that participants could unambiguously identify the agent and the patient in pictures, the agent was always on the left side of the picture, and with an arrow indicating the direction of objects. Each picture could be described in four ways, that is, a double-object datives description (henceforth, DO) and a prepositional-object datives description (henceforth, PO) in both Chinese and English. As Figure 1 shows, a DO description in English is "an artist hands a sailor a gun", a PO description in English is "an artist hands a gun to a sailor", a DO description in Chinese is “一个画家给一个水手一把手枪 (yige huajia gei yige shuishou yiba shouqiang)” and a PO description in Chinese is “一个画家给了一把手枪一个水手 (yige huajia geile yiba shouqiang yige shuishou)".

Each trial consisted of a picture accompanied by a priming sentence and a flag. The priming sentence was either a DO sentence or a PO sentence in Chinese or English. The flag was either a Chinese National flag or a British National flag. The two languages and two sentence types were combined into four conditions, distributing across all the trials. Specifically, for experimental and practice trials, when the priming sentence was in English, a Chinese National flag would be presented 


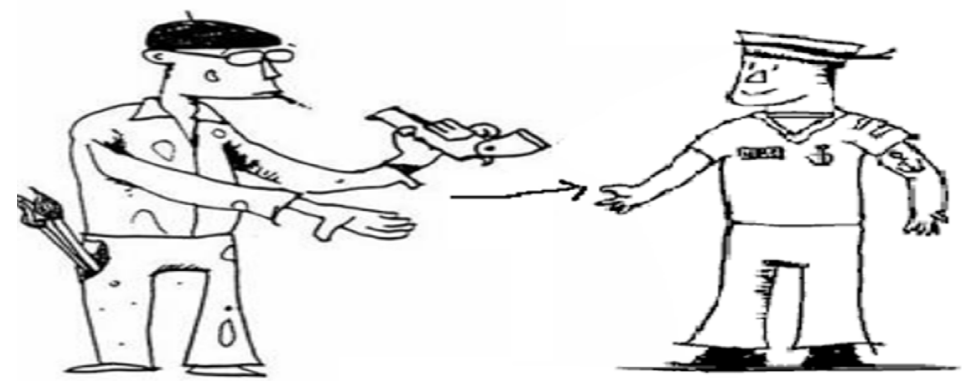

on the computer screen in order to produce a Chinese description of the picture; when the priming sentence was in Chinese, a British National flag would be presented on the computer screen in order to produce a English description of the picture. But for filler trials, the language of the priming sentence was consistent with the flag presented on the computer screen, that is to say, when the priming sentence was in Chinese, a Chinese National flag would be presented on the computer screen in order to produce a Chinese description of the picture; when the priming sentence was in English, a British National flag would be presented on the computer screen in order to produce a English description of the picture.

The forty-four pictures were pseudo-randomized and were counterbalanced so that each picture never occurred more than once.

\section{Research Design}

The research design is a 2 (language: Chinese vs. English) $\times 2$ (sentence type: DO vs. PO) factorial, with language and sentence type as independent variables, and the numbers of produced ChineseEnglish code-switched sentences as dependent variables.

\section{Tasks and Procedures}

Prior to the experiment, participants were familiar with the agents, actions, objects and patients that were used in the experiment by naming Chinese and English names of the agents, actions, objects and patients, so that code-switching during sentence production would not be influenced by problems in lexical access. This familiarization procedure is quite common in bilingual picture-naming studies (Costa \& Santesteban, 2004).

Before the experimental trials began, participants received spoken and written instructions to familiarize themselves with the procedures of the experiment. After instructions were given, participants were allowed to ask questions about the procedures. Participants were asked to do a 10min practice session with four practice trials to check whether instructions were fully understood and to familiar with the task. During the task, participants were asked to read aloud the priming sentence in Chinese or English at first, then to describe the picture on the computer screen in one sentence using the corresponding language according to the flag on the computer screen, and to write the target sentence in a piece of A4 paper. For instance, participants need to write the target sentence in English when a British National flag on the computer screen, or participants need to write the target sentence in Chinese when a Chinese National flag on the computer screen. To be specific, each trial started with the presentation of a fixation mark for $500 \mathrm{~ms}$. Then, the priming sentence was presented on the computer screen for 1,000 $\mathrm{ms}$ and disappeared. Then, the picture was presented on the computer screen for 5,000 ms and disappeared. Then, a national flag was presented on the computer screen for $500 \mathrm{~ms}$ and disappeared. After that, the computer screen turned to white, and participants wrote the 
Table 1. Numbers and Proportions of Produced Code-switched Sentences

\begin{tabular}{|l|c|c|}
\hline \multirow{2}{*}{ Sentence Type } & \multicolumn{2}{|c|}{ Prime-Target Language Combination } \\
\cline { 2 - 3 } & $\begin{array}{c}\text { The Chinese Priming Sentence, } \\
\text { The English Target Sentence }\end{array}$ & $\begin{array}{c}\text { The English Priming Sentence, } \\
\text { The Chinese Target Sentence }\end{array}$ \\
\hline Double-object dative (DO) & $278(20.4 \%)$ & $325(23.8 \%)$ \\
Same as the Priming Sentence & $66(4.8 \%)$ & $16(1.2 \%)$ \\
Different from the Priming Sentence & $285(20.9 \%)$ & $294(21.5 \%)$ \\
\hline Prepositional dative (PO) & $58(4.2 \%)$ & $44(3.2 \%)$ \\
Same as the Priming Sentence & & \\
Different from the Priming Sentence & & \\
\hline
\end{tabular}

target sentence in the corresponding language according to the flag in a piece of A4 paper as accurate and quickly as possible. After writing, participants pressed the space bar to start the next trial.

Participants were tested individually in a quiet room with one experimenter as a guider. Priming sentences, pictures and flags presentation, timing, and data collection were all controlled by E-prime 1.1. The whole experiment lasted about 40 minutes.

\section{RESULTS}

The target sentences describing the experimental pictures were scored as the code-switched sentences. Whether or not articles ' $a$ ' or 'the' were used, the target sentence was scored as long as it was grammatical. Incomplete and/or ungrammatical sentences were excluded. The total target codeswitched sentences of the thirty-two experimental trials were 1376 sentences, in which ten sentences $(0.7 \%)$ were excluded. The remaining 1366 target code-switched sentences are presented in Table 1. Figure 2 presents the proportions of produced code-switched sentences more visually.

A 2 (language) $\times 2$ (sentence type) ANOVA was performed to the data. The main effect of language was not significant, $F(1,42)=2.356, p=.132$. The main effect of sentence type was significant, $F(1,42)=20.317, p=.000$. The interaction effect between language and sentence type was also significant, $F(1,42)=7.706, p=.008$, indicating that participants were more likely to repeat the same syntactic structure in the code-switched target sentence as the syntactic structure of the priming sentence.

Figure 2. The Overall Proportions of Produced Code-switched Sentences
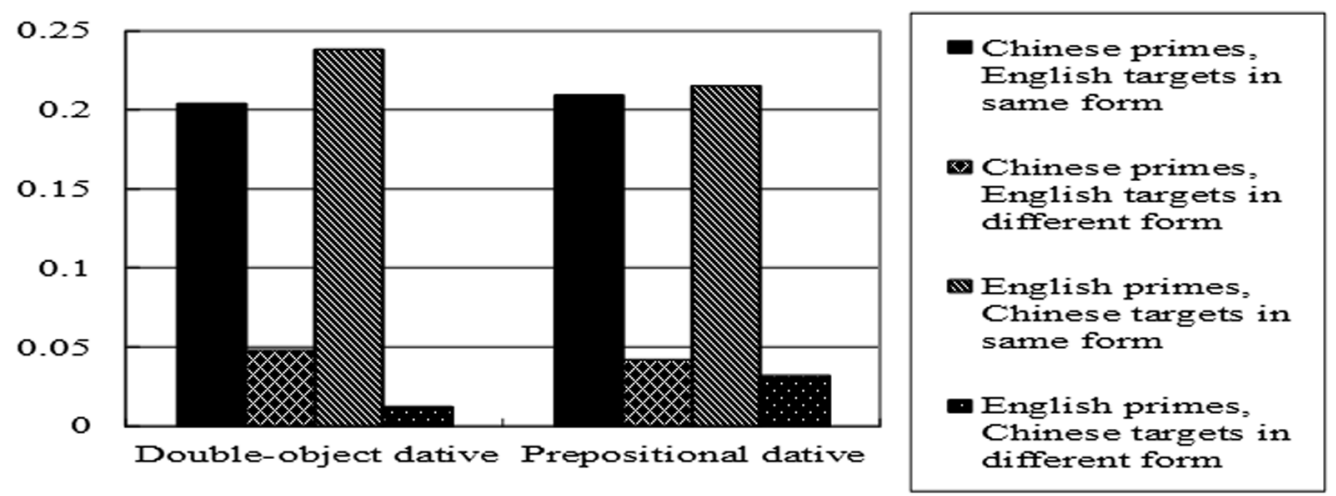


\section{DISCUSSION}

The main goal of the experiment presented here was to examine the effect of syntactic alignment on Chinese-English bilinguals' code-switched sentence production. The results showed that participants were more likely to use the same syntactic structure as the priming sentence during code-switched sentence production, thus indicating that there was an effect of syntactic alignment on Chinese-English bilinguals' code-switched sentence production. In other words, during Chinese-English code-switched sentence production, the effect of syntactic alignment facilitates an increased tendency for ChineseEnglish bilingual participants to use a DO or PO syntactic structure in Chinese after reading a DO or PO syntactic structure in English, and vice versa. To be specific, participants were more likely to use a DO syntactic structure in Chinese after reading a DO syntactic structure in English than after reading a PO syntactic structure in English. Also, participants were more likely to use a PO syntactic structure in Chinese after reading a PO syntactic structure in English than after reading a DO syntactic structure in English. In addition, participants were more likely to use a DO syntactic structure in English after reading a DO syntactic structure in Chinese than after reading a PO syntactic structure in Chinese. Also, participants were more likely to use a PO syntactic structure in English after reading a PO syntactic structure in Chinese than after reading a DO syntactic structure in Chinese. This is consistent with what has been suggested in the literature on structural priming during sentence production tasks (e.g. Bock, 1986; Bock \& Loebell,1990), suggesting that structural priming is reflected in the facilitation of an increased likelihood for speakers to repeat the same type of dative construction (double-object datives versus prepositional-object datives) in consecutive utterances.

In addition, when the priming sentence was in Chinese, compared with the numbers of codeswitched English sentences with the PO syntactic structure, the numbers of code-switched English sentences with the DO syntactic structure were less because of the more restricted use of DO syntactic structure in English, subject to lexical and dialectal variation. Conversely, compared with the numbers of code-switched Chinese sentences with the DO syntactic structure, the numbers of code-switched Chinese sentences in the PO syntactic structure were less because of the more restricted use of PO syntactic structure in Chinese, limited to certain conditions. Moreover, because participants were native Chinese speakers, there was an increased tendency for them to use idiomatic expression and fixed thinking pattern in Chinese, such as constructing the picture description based on the highlight degree of object or patient, that is, using the PO syntactic structure to highlight the object and using the DO syntactic structure to highlight the patient. Furthermore, although the verb and noun phrases varied between priming and target sentences, participants still showed the effect of structural priming during their code-switched sentence production, thus indicating the effect of syntactic alignment in the absence of any lexical repetition during Chinese-English bilinguals' code-switched sentence production.

The current study also combines linguistic and psycholinguistic theories and methodologies to examine the cognitive mechanism of code-switching between Chinese and English at sentencelevel, with the aim to extend the interactive alignment model (Pickering \& Garrod, 2004) and cross-language structural priming (e.g., Hartsuiker et al., 2004) to interpret bilingual code-switched sentence production. The interactive alignment model (Pickering \& Garrod, 2004) has proposed that speakers' representations link together at all linguistic levels of language processing and activated linguistic representations of language processing enables alignment to occur between speakers. Hence, alignment is a powerful mechanism interacting with speakers' syntactic choice in code-switching during sentence processing, indicating the effect of syntactic alignment on Chinese-English bilinguals' code-switched sentence production. According to the traditional monologue account, a certain message is encoded into an articulatory output, which develops through a step-by-step procedure with a fixed directionality from intention to selection of words and syntax for articulation (e.g., Levelt, 1989; Garrod \& Pickering, 2007). According to the dialogue account, dialogue is an essentially joint process, which has a significant effect on interlocutors' contributions to the conversation. Interlocutors come 
to a common conception of what they are talking about, otherwise, the dialogue would fail (e.g., Garrod \& Pickering, 2004; Pickering \& Garrod, 2004; Schober, 2006). In order to achieve common understanding, interlocutors in dialogue coordinate and accommodate their linguistic choices to facilitate their language production (e.g., Garrod \& Pickering, 2004, 2007; Schober, 2006). Instead of starting every utterance from scratch, interlocutors make shortcuts in their language production by using each other's words, syntactic constructions and so on, resulting in an increased mutual understanding during ongoing conversation (Garrod \& Pickering, 2004; Schober, 2006). Linguistic coordination and interaction is grounded in the social, situational, and conversational circumstances in which it takes place. Situational dimensions of discourse as well as linguistic items and/or structures at each level could be language-specific or shared between languages, which forms the basis of specific patterns of code-switching in rich discourse situations (Kootstra et al., 2009; Kootstra et al., 2010). In general, during sentence production, a speaker must retrieve correct words from mental lexicon, and then, put these words in a sentence structure conforming to grammatical rules of the language he or she speaks, avoiding grammatical errors or syntactic ambiguities. For bilingual speakers, this coordination between selection of words and construction of syntactic structures becomes even more complex, as bilingual speakers have to make sure that words and syntactic structures of each language are correctly selected (Hartsuiker \& Pickering, 2008). Closely related languages or members of the same language family, such as Germanic and Romance languages often show strong structural similarities, for example, double-object datives and prepositional-object datives are structurally identical in English, Dutch, German, Swedish and Frisian. Syntactic choice in the encoding of codeswitched sentences is a dynamic bilingual processing in which intra- and inter-individual mechanisms of two different languages co-activate. When there are more shared syntactic elements between two different languages, shared syntactic representation is more easily to be activated, therefore, codeswitched sentence occurs more often. In view of this, shared syntactic representation between Chinese and English are interactive with each other, leading to syntactic alignment during Chinese-English bilinguals' code-switched sentence production.

In summary, the current study has not only confirmed the effect of syntactic alignment on ChineseEnglish bilinguals' code-switched sentence production, but also extended cross-language structural priming and the interactive alignment model (Garrod \& Pickering, 2004) to interpret code-switching during bilingual sentence production.

\section{CONCLUSION}

A structural priming experiment was conducted to explore the effect of syntactic alignment on Chinese-English bilinguals' code-switched sentence production. A main conclusion present here is that there is an effect of syntactic alignment on code-switching between Chinese and English during sentence production, specifically, the effect of syntactic alignment facilitates the likelihood for Chinese-English bilinguals to produce code-switched sentence with the same syntactic structure as the priming sentence. The results add to a growing body of empirical evidence from studies highlighting the role of cross-language structural priming, also providing additional evidence to support the interactive alignment model (Garrod \& Pickering, 2004). Code-switching is affected by multiple linguistic representations at all levels of language processing, and alignment is a powerful mechanism of syntactic choice in code-switching. Therefore, consistent with the findings of previous studies concerning the mechanism of code-switched sentence production among alphabetic words, this study confirm the effect of syntactic alignment on Chinese-English bilinguals' code-switched sentence production, and extend the universality of the interactive alignment model to interpret codeswitching and bilingual language processing.

There are still a few limitations due to the complexity of bilingual code-switched sentence production and the inadequacy of the author's personal understanding. One limitation may result from the sample of participants. The sample size used in the current study is confined to proficient 
Chinese-English bilinguals. Therefore, the results may not be generalized to other non-proficient Chinese-English bilinguals. Another limitation is that the function of recording responding times by E-prime software was not fully applied in the current study. In other words, whether participants generate a faster respond when using repeated syntactic structure or not is unknown, which awaits further investigation. Further study can be conducted to examine cognitive and neural mechanisms underlying Chinese-English bilinguals' code-switched sentence production using eye-tracking, EEG and/or fMRI techniques. Also, future research can be conducted to study Chinese-English bilinguals' code-switched sentence comprehension, thus provide a comprehensive picture of Chinese-English bilinguals' code-switching at sentence-level, and more in general, advance knowledge for theories in code-switching and bilingual language processing.

\section{ACKNOWLEDGMENT}

I am very grateful to my supervisor Professor Lin Fan for helpful discussions, suggestions, and comments on the study and manuscripts. I am also very grateful to Professor Gerrit Jan Kootstra, Professor Martin J. Pickering, and Professor Holly P. Branigan for sharing their studies and materials. I am also very grateful to Zhen Wang for assistance in data collection. Many thanks to the anonymous reviewers, and their valuable comments have improved the article.

\section{FUNDING}

This research was supported by the University Scientific Research Project of Huzhou University [2019XJWK10/KX20116]; the Postgraduate Scientific and Innovative Research Project of Ningbo University [G11JB005]; and the Excellent Postgraduate Dissertation Project of Ningbo University [PY20100016].

\section{COMPETING INTERESTS}

The author declared no potential competing interests with respect to the research, authorship, and/ or publication of this article. 


\section{REFERENCES}

Abutalebi, J., \& Green, D. W. (2007). Bilingual language production: The neurocognition of language representation and control. Journal of Neurolinguistics, 20(3), 242-275. doi:10.1016/j.jneuroling.2006.10.003

Auer, J. C. P. (1998). Code-switching in conversation: Language, interaction, and identity. Routledge.

Bernolet, S., Hartsuiker, R. J., \& Pickering, M. J. (2007). Shared syntactic representations in bilinguals: Evidence for the role of word order repetition. Journal of Experimental Psychology. Learning, Memory, and Cognition, 33(5), 931-949. doi:10.1037/0278-7393.33.5.931 PMID:17723070

Blom, J. P., \& Gumperz, J. J. (1972). Social meaning in linguistic structures: Code switching in northern Norway. In J. J. Gumperz \& Del Hymes (Eds.), Directions in Sociolinguistics: The Ethnography of Communication (pp. 407-434). New York: Holt, Rinehart, and Winston.

Bock, J. K. (1986). Syntactic persistence in language production. Cognitive Psychology, 18(3), 355-387. doi:10.1016/0010-0285(86)90004-6

Branigan, H. P., Pickering, M. J., \& Cleland, A. A. (2000). Syntactic coordination in dialogue. Cognition, 75(2), B13-B25. doi:10.1016/S0010-0277(99)00081-5 PMID:10771277

Branigan, H. P., Pickering, M. J., Mclean, J. F., \& Cleland, A. A. (2007). Syntactic alignment and participant role in dialogue. Cognition, 104(2), 163-197. doi:10.1016/j.cognition.2006.05.006 PMID:16876778

Branigan, H. P., Pickering, M. J., Stewart, A. J., \& Mclean, J. F. (2000). Syntactic priming in spoken production: Linguistic and temporal interference. Memory \& Cognition, 28(8), 1297-1302. doi:10.3758/BF03211830 PMID:11219957

Cheung, H., \& Chen, H. C. (1998). Lexical and conceptual processing in Chinese-English bilinguals: Further evidence for asymmetry. Memory \& Cognition, 26(5), 1002-1013. doi:10.3758/BF03201179 PMID:9796232

Cleland, A. A., \& Pickering, M. J. (2003). The use of lexical and syntactic information in language production: Evidence from the priming of noun-phrase structure. Journal of Memory and Language, 49(2), 214-230. doi:10.1016/S0749-596X(03)00060-3

Costa, A., \& Caramazza, A. (1999). Is lexical selection in bilinguals language-specific? Further evidence from Spanish-English bilinguals and English-Spanish bilinguals. Bilingualism: Language and Cognition, 2, 231-244. doi:10.1017/S1366728999000334

Costa, A., Pickering, M. J., \& Sorace, A. (2008). Alignment in second language dialogue. Language and Cognitive Processes, 23(4), 528-556. doi:10.1080/01690960801920545

Costa, A., \& Santesteban, M. (2004). Lexical access in bilingual speech production: Evidence from language switching in highly proficient bilinguals and L2 learners. Journal of Memory and Language, 50(4), 491-511. doi:10.1016/j.jml.2004.02.002

Costa, A., Santesteban, M., \& Ivanova, I. (2006). How do highly proficient bilinguals control their lexicalization process? Inhibitory and language-specific selection mechanisms are both functional. Journal of Experimental Psychology. Learning, Memory, and Cognition, 32, 1057-1074.

Desmet, T., \& Declercp, M. (2006). Cross-linguistic priming of syntactic hierarchical configuration information. Journal of Memory and Language, 54(4), 610-632. doi:10.1016/j.jml.2005.12.007

Ferreira, V. S., \& Bock, K. (2006). The functions of structural priming. Language and Cognitive Processes, 21(7-8), 1011-1029. doi:10.1080/01690960600824609 PMID:17710210

Francis, W. S. (1999). Cognitive integration of language and memory in bilinguals: Semantic representation. Psychological Bulletin, 125(2), 193-222. doi:10.1037/0033-2909.125.2.193 PMID:10087936

Garrod, S., \& Pickering, M. J. (2004). Why is conversation so easy? Trends in Cognitive Sciences, 8(1), 8-11. doi:10.1016/j.tics.2003.10.016 PMID:14697397

Garrod, S., \& Pickering, M. J. (2007). Automaticity of language production in monologue and dialogue. In A. S. Meyer, L. R. Wheeldon, \& A. Krott (Eds.), Automaticity and Control in Language Processing. Psychology Press. 
Green, D. W. (1998). Mental control of the bilingual lexico-semantic system. Bilingualism: Language and Cognition, 1(2), 67-81. doi:10.1017/S1366728998000133

Gries, S. T. (2005). Syntactic priming: A corpus-based approach. Journal of Psycholinguistic Research, 34(4), 365-399. doi:10.1007/s10936-005-6139-3 PMID:16142588

Gullberg, M., Indefrey, P., \& Muysken, P. (2009). Research techniques for the study of code-switching. In B. E. Bullock \& A. J. Toribio (Eds.), The Cambridge Handbook of Linguistic Code-switching (pp. 21-39). Cambridge University Press. doi:10.1017/CBO9780511576331.003

Hartsuiker, R. J., \& Pickering, M. J. (2008). Language integration in bilingual sentence production. Acta Psychologica, 128(3), 470-489. doi:10.1016/j.actpsy.2007.08.005 PMID:17870040

Hartsuiker, R. J., Pickering, M. J., \& Veltkamp, E. (2004). Is syntax separate or shared between languages? Cross-linguistic syntactic priming in Spanish/English bilinguals. Psychological Science, 15(6), 409-414. doi:10.1111/j.0956-7976.2004.00693.x PMID:15147495

Hernandez, A. E., Dapretto, M., Mazziotta, J., \& Bookheimer, S. (2001). Language switching and language representation in Spanish-English bilinguals: An fMRI study. NeuroImage, 14(2), 510-520. doi:10.1006/ nimg.2001.0810 PMID:11467923

Huttenlocher, J., Vasilyeva, M., \& Shimpi, P. (2004). Syntactic priming in young children. Journal of Memory and Language, 50(2), 182-195. doi:10.1016/j.jml.2003.09.003

Isurin, L., Winford, D., \& de Bot, K. (2009). Interdisciplinary Approaches to Code-switching. John Benjamins. doi:10.1075/sibil.41

Kootstra, G. J., van Hell, J. G., \& Dijkstra, T. (2009). Two speakers, one dialogue: An interactive alignment perspective on code-switching in bilingual speakers. In L. Isurin, D. Winford, \& K. de Bot (Eds.), Interdisciplinary Approaches to Code Switching (pp. 129-160). John Benjamins. doi:10.1075/sibil.41.09koo

Kootstra, G. J., van Hell, J. G., \& Dijkstra, T. (2010). Syntactic alignment and shared word order in code-switched sentence production: Evidence from bilingual monologue and dialogue. Journal of Memory and Language, 63(2), 210-237. doi:10.1016/j.jml.2010.03.006

Kroll, J. F., Bobb, S. C., Misra, M., \& Guo, T. (2008). Language selection in bilingual speech: Evidence for inhibitory processes. Acta Psychologica, 128(3), 416-430. doi:10.1016/j.actpsy.2008.02.001 PMID:18358449

Kroll, J. F., Bobb, S. C., \& Wodniecka, Z. (2006). Language selectivity is the exception, not the rule: Arguments against a fixed locus of language selection in bilingual speech. Bilingualism: Language and Cognition, 9(2), 119-135. doi:10.1017/S1366728906002483

Kroll, J. F., \& Stewart, E. (1994). Category interference in translation and picture naming: Evidence for asymmetric connections between bilingual memory representations. Journal of Memory and Language, 33(2), 149-174. doi:10.1006/jmla.1994.1008

Levelt, W. J. M. (1989). Speaking: From intention to articulation. MIT Press.

Levelt, W. J. M., \& Kelter, S. (1982). Surface form and memory in question answering. Cognitive Psychology, 14(1), 78-106. doi:10.1016/0010-0285(82)90005-6

Loebell, H., \& Bock, K. (2003). Structural priming across languages. Linguistics, 41(5), 791-824. doi:10.1515/ ling.2003.026

MacSwan, J. (2000). The architecture of the bilingual language faculty: Evidence from intrasentential code switching. Bilingualism: Language and Cognition, 3(1), 37-54. doi:10.1017/S1366728900000122

McDonough, K. (2006). Interaction and syntactic priming: English L2 speakers' production of dative constructions. Studies in Second Language Acquisition, 28(02), 179-207. doi:10.1017/S0272263106060098

Meuter, R. F. I., \& Allport, T. A. (1999). Bilingual language switching in naming: Asymmetrical costs of language selection. Journal of Memory and Language, 40(1), 25-40. doi:10.1006/jmla.1998.2602

Muysken, P. (2000). Bilingual Speech: A Typology of Code-mixing. Cambridge University Press.

Myers-Scotton, C. (1993). Social Motivations for Code-switching: Evidence from Africa. Oxford University Press. 
Myers-Scotton, C. (2002). Contact Linguistics: Bilingual Encounters and Grammatical Outcomes. Oxford University Press. doi:10.1093/acprof:oso/9780198299530.001.0001

Orfanidou, E., \& Sumner, P. (2005). Language switching and the effects of orthographic specificity and response repetition. Memory \& Cognition, 33(2), 355-369. doi:10.3758/BF03195323 PMID:16028589

Paradis, M. (1997). The cognitive neuropsychology of bilingualism. In A. M. B. de Groot \& J. F. Kroll (Eds.), Tutorials in Bilingualism (pp. 331-354). Lawrence Erlbaum Associates.

Pardo, J. S. (2006). On phonetic convergence during conversational interaction. The Journal of the Acoustical Society of America, 119(4), 2382-2393. doi:10.1121/1.2178720 PMID:16642851

Pickering, M. J., \& Branigan, H. P. (1998). The representation of verbs: Evidence from syntactic persistence in written language production. Journal of Memory and Language, 39(4), 633-651. doi:10.1006/jmla.1998.2592

Pickering, M. J., \& Branigan, H. P. (1999). Syntactic priming in language production. Trends in Cognitive Sciences, 3(4), 136-141. doi:10.1016/S1364-6613(99)01293-0 PMID:10322467

Pickering, M. J., \& Ferreira, V. S. (2008). Structural priming: A critical review. Psychological Bulletin, 134(3), 427-459. doi:10.1037/0033-2909.134.3.427 PMID:18444704

Pickering, M. J., \& Garrod, S. (2004). Toward a mechanistic psychology of dialogue. Behavioral and Brain Sciences, 27(02), 169-226. doi:10.1017/S0140525X04000056 PMID:15595235

Pickering, M. J., \& Garrod, S. (2006). Alignment as the basis for successful communication. Research on Language and Computation, 4(2-3), 203-228. doi:10.1007/s11168-006-9004-0

Poplack, S. (1980). Sometimes I'll start a sentence in Spanish Y TERMINO EN ESPANOL: Toward a typology of code-switching. Linguistics, 18(7-8), 581-618. doi:10.1515/ling.1980.18.7-8.581

Salamoura, A., \& Williams, J. N. (2007). Processing verb argument structure across languages: Evidence for shared representations in the bilingual lexicon. Applied Psycholinguistics, 28(4), 627-660. doi:10.1017/ S0142716407070348

Schober, M. F. (2006). Dialogue and interaction. In K. Brown (Ed.), Encyclopedia of Language and Linguistics (pp. 564-571). Elsevier. doi:10.1016/B0-08-044854-2/00792-6

Schoonbaert, S., Hartsuiker, R. J., \& Pickering, M. J. (2007). The representation of lexical and syntactic information in bilinguals: Evidence from syntactic priming. Journal of Memory and Language, 56(2), 153-171. doi:10.1016/j.jml.2006.10.002

Smith, M., \& Wheeldon, L. (2001). Syntactic priming in spoken sentence production - an online study. Cognition, 78(2), 123-164. doi:10.1016/S0010-0277(00)00110-4 PMID:11074248

Spinks, K., \& Gelder, D. (1994). Asymmetrical cross-language priming effects. Journal of Experimental Psychology. Learning, Memory, and Cognition, 22, 70-84. PMID:8035687

Thomas, M. S. C., \& Allport, A. (2000). Language switching costs in bilingual visual word recognition. Journal of Memory and Language, 43(1), 44-66. doi:10.1006/jmla.1999.2700

van Beijsterveldt, L. M., \& van Hell, J. G. (2009). Structural priming of adjective-noun structures in hearing and deaf children. Journal of Experimental Child Psychology, 104(2), 179-196. doi:10.1016/j.jecp.2009.05.002 PMID:19497585

van Hell, J. G., \& Witteman, M. J. (2009). The neurocognition of switching between languages: A review of electrophysiological studies. In L. Isurin, D. Winford, \& K. de Bot (Eds.), Interdisciplinary Approaches to Code-switching (pp. 53-84). John Benjamins. doi:10.1075/sibil.41.06hel

Weber, K., \& Indefrey, P. (2009). Syntactic priming in German-English bilinguals during sentence comprehension. NeuroImage, 46(4), 1164-1172. doi:10.1016/j.neuroimage.2009.03.040 PMID:19328233

Wei, L. (2007). Dimensions of bilingualism. In L. Wei (Ed.), The Bilingualism Reader (2nd ed., pp. 3-22). Routledge. 
Wei, L., Milroy, L., \& Ching, P. S. (1992). A two-step sociolinguistic analysis of code-switching and language choice: The example of a bilingual Chinese community in Britain. International Journal of Applied Linguistics, 2(1), 63-86. doi:10.1111/j.1473-4192.1992.tb00024.x

Zield, K. M., Phillipe, A. P., \& Karine, P. (2006). Bilingualism and adult differences in inhibitory mechanisms: Evidence from a bilingual Stroop task. Brain and Cognition, 54, 254-256. PMID:15050787

Zwaan, R. A., \& Radvansky, G. A. (1998). Situation models in language comprehension and memory. Psychological Bulletin, 123(2), 162-185. doi:10.1037/0033-2909.123.2.162 PMID:9522683 


\section{APPENDIX}

\section{Stimuli Used in the Experimental and Filler Trials}

1. A teacher gives a banana to a swimmer. / A teacher gives a swimmer a banana.

\section{NUN SHOW DOCTOR CAKE}

2. A teacher gives an apple to a doctor. / A teacher gives a doctor an apple.

\section{PIRATE SEND SAILOR CAKE}

3. A chef hands a hat to a sailor. / A chef hands a sailor a hat.

POLICEMAN THROW SWIMMER CUP

4. A chef hands a ball to a boxer. / A chef hands a boxer a ball.

\section{NUN SELL GIVE MONK BANANA}

5. A pirate shows a book to a monk. / A pirate shows a monk a book.

\section{ARTIST OFFER DANCER GUN}

6. A pirate shows a cake to a soldier. / A pirate shows a soldier a cake.

\section{DOCTOR SEND DANCER CUP}

7. A waitress sends a spoon to a dancer. / A waitress sends a dancer a spoon.

BOXER HAND PROFESSOR APPLE

8. A chef sends a carrot to a doctor. / A chef sends a doctor a carrot.

\section{FARMER GIVE COWBOY HEN}

9. A cowboy offers a gun to a soldier. / A cowboy offers a soldier a gun.

\section{CHEF SEND SWIMMER JUG}

10. A pirate offers a key to a burglar. / A pirate offers a burglar a key.

\section{NUN THROW MONK APPLE}

11. 海盗给了一顶帽子小偷。 / 海盗给小偷一顶帽子。 
12. 画家递了一个球小丑。 / 画家递给小丑一个球。

\title{
DANCER GIVE SOLDIER CUP
}

13. 警察给了一根香蕉游泳者。 / 警察给游泳者一根香蕉。

\section{ARTIST SEND SAILOR BOOK}

14. 服务员送了一个蛋糕教授。/ 服务员送给教授一个蛋糕。

\section{PIRATE SHOW SWIMMER BOX}

15. 僧人给了一本书男孩。／僧人交给男孩一本书。

\author{
FARMER THROW WAITRESS GOOSE
}

16. 厨师扔了一只鸭子农夫。/ 厨师扔给农夫一只鸭子。

\section{COWBOY HAND MONK CIGARETTE}

17. 海盗递了一个箱子游泳者。 / 海盗递给游泳者一个箱子。

\section{POLICEMAN SEND PROFESSOR CHAIN}

18. 僧人送了一个球警察。／僧人送给警察一个球。

\section{DANCER GIVE WAITRESS SHOE}

19. 男孩递了一本书画家。／男孩递给画家一本书。

\author{
POLICEMAN THROW SAILOR HAMMER
}

20. 牛仔给了一把刀拳击手。 / 牛仔交给拳击手一把刀。

\author{
SOLDIER HAND CLOWN DOG
}

\begin{abstract}
Mengling Xu received one MA degree in Foreign Linguistics and Applied Linguistics from Ningbo University, China in March, 2012 and the other MA degree in Linguistics and English Language Teaching from University of Leeds, UK in October, 2013. Then, she received her PhD degree in Linguistics from the University of Leeds, UK in January 2018. After graduation, she worked as a short-term Postdoc researcher at Leeds Humanities Research Institute of University of Leeds, UK. In November, 2018, she was hired as a lecturer in English and Linguistics at Huzhou University, Zhejiang, China. Her research interests mainly focus on psycholinguistics, Chinese-English bilingualism and second language acquisition.
\end{abstract}

